\title{
Addressing sea safety in Cyprus
}

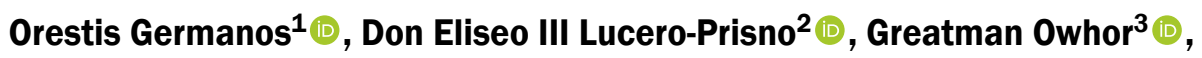 \\ Eleni Xenofontos ${ }^{1}$, Antonis Nteveros ${ }^{1}$ (i) \\ ${ }^{1}$ Medical School of University of Cyprus, Cyprus \\ ${ }^{2}$ London School of Hygiene and Tropical Medicine, London, United Kingdom \\ ${ }^{3}$ University of Calabar Teaching Hospital, Cross River State, Nigeria
}

Cyprus is an island that is surrounded by water from the Mediterranean Sea [1]. The definition of the word "island", which is a land smaller than a continent and surrounded by water, induces how important and beneficial the sea is to Cyprus for achieving their annual revenue and goals in the sectors of marine trading, tourism, swimming, and transportation. As a result, we would like to address the topic of "sea safety in Cyprus", not only to identify the gaps of it, but also enhance it with new preventative ideas.

Sea safety involves the enforcement of desirable conditions of human activity at sea, to eliminate any form of danger to human life, property, and the marine environment [2]. Accidents may occur in the seas of Cyprus. These accidents occur mainly by boat wrecks or drowning from swimming. A famous shipwreck accident in Cyprus is the Edro III Shipwreck, which started its journey at Sierra, Leone, then had a stop at Limassol's port with its final destination being Rhodes. The ship was carrying 9 sailors when a rough storm severely damaged it in the Chloraka area of Paphos, but luckily all these sailors were saved by a helicopter of the British military. This incident, since 2011, has been famous for tourists, because the shipwreck can be seen from the shore [3].

The most recent drowning occurred on the $18^{\text {th }}$ of September 2021 at Latchi, where a man was found dead in the sea [4]. In certain areas of Cyprus, especially in Paphos, the seas are coded as red dangerous areas. This indicates possible water currents or big waves, but most people are not aware of these codes and what they mean in the sea of Cyprus. As a result, I would like to make some recommendations that could help increase safety in the seas of Cyprus. Safety is crucial; it is a basic principle for conducting any activity within or around the sea. Important factors such as effective technology for communication such as satellites must be prioritised [5]. The legislation needs to address matters relating to seafarers' health, decision-making, exchange of information, and safety culture.

Drowning occurs more often to people that do not have the necessary swimming skills; as a result, the government should contribute to developing the necessary skills of swimming for every person capable of learning. This will help to reduce the number of deaths caused by drowning. To supplement swimming, more efforts should be placed on search and rescue; this can include the recruitment of rescue staff and training of members of the public on the basic rescue techniques with a focus on drowning.

The Ministry of Health and Education should mandate all people taking courses on sea safety or even these courses could be offered free, to all citizens above 18 years old.

Concluding, our call to action to the government of Cyprus is to apply the above thoughts in their policy strategy to increase the sea safety of Cyprus.

\section{Conflict of interest: None declared}

\section{REFERENCES}

1. Cyprus country profile. Nations online (1974). ttps://www.nationsonline.org/oneworld/cyprus.html (EC 61508-1:2010).

2. Functional safety of electrical/electronic/programmable electronic safety-related systems - Part 1: General requirements. Edition 2. International Electrotechnical Commission, Genève, 2010.

3. https://www.cyprusisland.net/cyprus-shipwrecks/edro-iii-shipwreck.

4. https://cyprus-mail.com/2021/09/18/man-found-dead-in-sea-off-latchi/.

5. Formela K, Neumann T, Weintrit A. Overview of Definitions of Maritime Safety, Safety at Sea, Navigational Safety and Safety in General. TransNav, the International Journal on Marine Navigation and Safety of Sea Transportation. 2019; 13(2): 285-290, doi: 10.12716/1001.13.02.03.

Orestis Germanos, medical student, Nikolaou Katounta 6, 2103, Nicosia, Cyprus, tel/fax: +35797734411, e-mail: orestisger@gmail.com

This article is available in open access under Creative Common Attribution-Non-Commercial-No Derivatives 4.0 International (CC BY-NC-ND 4.0) license, allowing to download articles and share them with others as long as they credit the authors and the publisher, but without permission to change them in any way or use them commercially. 